\title{
Plackett-Burman Design of Environmental and Nutritional Parameters for Petroleum Bioremediation by Penicillium chresogenum
}

\author{
Talaat A. Hegazy ${ }^{1}$, M. S. ${ }^{*}$ Ibrahim $^{1}$ and Hazem T. Abdel Hamid ${ }^{1}$ \\ ${ }^{1}$ Department of Environmental Sciences, Faculty of Science, Damietta University, Egypt.
}

Received: 24 May 2015 / Accepted: 20 September 2015

*Corresponding author: mahmoudsalem1912@gmail.com

\begin{abstract}
Bioremediation of diesel oil using microbial species is a promising method to remedy contaminated soil using Penicillium chresogenum. In this study, Plackett-Burman experiment is a new model for diesel oil degradation. It may save time and efforts relatively, simple in addition to making one experiment for many variables. In this study Plackett-Burman experimental design had been applied to estimate the significant of nutritional conditions affecting petroleum bioremediation by isolated Penicillium chresogenum. Eleven variables through 12 trials were studied in this experiment, namely ammonium sulphate, potassium carbonate, potassium dihydrogen phosphate, sodium dihydrogen phosphate, beef extract, spore suspension, sodium chloride, magnesium sulphate, calcium chloride, temperature and $\mathrm{pH}$. It was found that four variables (spore suspension, (NH4)2SO4, Potassium Carbonate, and Magnesium sulphate) are affected the bioremediation process positively, while others (sodium dihydrogen phosphate, Beef extracts, Temperature, $\mathrm{pH}$, Sodium chloride, $\mathrm{NaCl}$ and $\mathrm{KH} 2 \mathrm{PO} 4$ ) have negative effects on oil bioremediation. Depending on petroleum weight loss calculations, and the above variables parameters the petroleum oil was removed by Penicillium chresogenum. Both, sodium chloride and temperature were found to inhibit its removal process. The experiment No (9) using Pencillium chresogenum was considered that the most suitable method for oil degradation with percentage removal of petroleum $97.9 \%$. On the hand, experiment No (10) the undesirable method for oil removal with percentage removal $4.09 \%$. Based on the experiment, a microbiological model is constructed to simulate microbial growth and oil decomposition. Biodegradation rate was influenced by oil concentration, temperature, water content and oxygen concentration.
\end{abstract}

Keywords: Fungi, Petroleum bioremediation, Oil removal, Marine sediment, Plackett-Burman Modeling.

\section{Introduction}

Coastal pollution by oil was found to be a very dangerous problem along the Mediterranean Sea.
Hydrocarbons may come to the marine environments by anthropogenic sources such as manufacturing, refining installation, oil tanker spills; direct discharge from effluent treatment plants and accidents during transportation of the 
crude oil (Heul, 2009). Diesel oil is a pollutant that frequently is reported as soil contaminant (Wang et al., 2005; Ciric et al., 2009). Above a certain level diesel pollution can be toxic to plants and microorganisms (Tesar et al., 2002; Adam and Duncan, 2003; Lapinskienè et al., 2006).The increase in particulate phase hydrocarbon in winter is related to the increase in the use of domestic heating, traffic congestion, less pollutant dispersal due to meteorological conditions and the absence of photochemical degradation that occurs in summer. Bioremediation is the metabolic ability of microorganisms (Yeast, fungi, or bacteria) to transform or minimize toxic organic contaminants present in soils, sediments and water into less harmful substances. The activity of microorganisms is stimulated by many factors that affect the biodegradation of petroleum hydrocarbons such as temperature, oxygen, micro and macro nutrients, $\mathrm{pH}$, Solubility, concentration of hydrocarbon. Fungi are also known to degrade hydrocarbons and are suitable for the five-ring PAHs, which are only poorly degraded by bacteria. To make a suitable bioremediation application, it can take long time and may be affecting by some factors which inhibit degradation of hydrocarbons. Anew model was proposed for using the best method for degradation of diesel oil. This method depends on using a fungal isolates from Pencillium chresogenum. The main method that has been used for using many factors by changing of one variable at a time method. This is an experimental method in which single factors varied, while other factors are kept constant at specific set of conditions. This method leads to unreliable results and wrong conclusions, and is inferior to the factorial design method (Krishnan et al., 1998). So, the application of this design is suitable for large number of cultural conditions under investigation. Plackett-Burman design (Plackett and Burman, 1946) comprises one type of a twolevel screening design. It is favored to detect the significant factors affecting the process before proceeding to the optimization stage of experimental design. The aim of this work is to investigate the bioremediation of petroleum oil by a Penicillium chresogenum. and applying a thorough optimization process. The main objective was to evaluate the effects of nutritional conditions, represented as media components and environmental factors, on the bioadsorption and biodegradation of petroleum oil. This is needed to develop a near optimal medium in order to enhance the bioremediation process by means of statistically designed experiments. Abdel-Fattah et al. (2002).

\section{MATERIALS AND METHODS}

\section{Media preparation}

The enrichment procedure as described by Nwachukwu (2000) was used in the estimation of hydrocarbon utilizes. A minimal salt broth containing $2.0 \mathrm{~g}$ of $\mathrm{Na}_{2} \mathrm{HPO}_{4}, 0.17 \mathrm{~g}$ of $\mathrm{K}_{2} \mathrm{SO}_{4}, 4.0 \mathrm{~g}$ of $\mathrm{NH}_{4} \mathrm{NO}_{3}, 0.53 \mathrm{~g}$ of $\mathrm{KH}_{2} \mathrm{PO}_{4}, 0.10 \mathrm{~g}$ of $\mathrm{MgSO}_{4}$. $7 \mathrm{H}_{2} \mathrm{O}$ and $5.0 \mathrm{~g}$ of agar - agar dissolved in $1000 \mathrm{ml}$ of distilled water was prepared. The solution was sterilized by autoclaving. Diesel oil is added as main carbon source in concentration of $0.5 \% \mathrm{v} / \mathrm{v}$.

\section{Isolation of Pencillium chresogenum}

Plates were incubated at room temperature $\left(28^{\circ}-\right.$ $30^{\circ} \mathrm{C}$ ) for 5 to 10 days. The fungus used in this study was isolated from minimal salt broth medium. It was purified and identified morphologically as Penicillium chresogenum.

\section{Spore suspension preparation}

Slants of minimal salt broth medium were inoculated with fungal spores and incubated till the appearance of spores. $3 \mathrm{ml}$ of sterile distilled water was added to each slant and spore suspension was stored under refrigeration.

\section{Plackett-Burman microcosm}

Every variable was prepared from stock solution to obtain accurate results. Environmental factors have been evaluated. The different factors were prepared in two levels: -1 for low concentration and +1 for high concentration, depending on Plackett- Burman modeling design (Plackett and Burman, 1946). A control experiment was made for every trail in this design as the same manner of experiment without spore suspension. Table (1) illustrates the factors under investigation and their levels that used in this design. Petroleum oil concentration was kept constant in all trials at the level of $0.5 \%$. 
Table (1): List of variables under study and their coded levels.

\begin{tabular}{|c|c|l|c|c|l|c|}
\hline No & Factor & Factor Name & Conc \% & Low $(-1)$ & Conc \% & High(+1) \\
\hline 1 & A & Ammonium Sulphate & $0.4(\mathbf{w} / \mathbf{v})$ & -1 & $1.2(\mathbf{w} / \mathbf{v})$ & +1 \\
\hline 2 & B & Potassium Carbonate & $0.03(\mathbf{w} / \mathbf{v})$ & -1 & $0.6(\mathbf{w} / \mathbf{v})$ & +1 \\
\hline 3 & C & Sodium dihydrogen phosphate & $0.2(\mathbf{w} / \mathbf{v})$ & -1 & $0.9(\mathbf{w} / \mathbf{v})$ & +1 \\
\hline 4 & D & Beef extract & $0.02(\mathrm{w} / \mathrm{v})$ & -1 & $0.5(\mathbf{w} / \mathbf{v})$ & +1 \\
\hline 5 & E & Spore suspension volume & $3 \mathrm{ml}$ & -1 & $6 \mathrm{ml}$ & +1 \\
\hline 6 & F & Temperature & $30^{\circ} \mathrm{c}$ & -1 & $40^{\circ} \mathrm{c}$ & +1 \\
\hline 7 & $\mathrm{G}$ & pH (alkaline- acidic) & 4 & -1 & 7.5 & +1 \\
\hline 8 & $\mathrm{H}$ & Sodium chloride & $0.3(\mathbf{w} / \mathbf{v})$ & -1 & $2(\mathbf{w} / \mathbf{v})$ & +1 \\
\hline 9 & J & Magnesium sulphate & $1.2(\mathbf{w} / \mathbf{v})$ & -1 & $2(\mathbf{w} / \mathbf{v})$ & +1 \\
\hline 10 & K & Calcium chloride & $0.1(\mathbf{w} / \mathbf{v})$ & -1 & $0.5(\mathbf{w} / \mathbf{v})$ & +1 \\
\hline 11 & L & Potassium dihydrogenphosphate & $0.4(\mathbf{w} / \mathbf{v})$ & -1 & $0.1(\mathbf{w} / \mathbf{v})$ & +1 \\
\hline
\end{tabular}

\section{Plackett-Burma experimental design}

For screening purpose, various medium components have been evaluated using PlackettBurman (PB) statistical design (Plackett and Burman, 1946). The different factors were prepared in two levels: -1 for low level and +1 for high level. Table (1) illustrates the factors under investigation as well as levels of each factor used in the experimental design. The nitrogen compounds were prepared in equimolar bases to give $0.2 \mathrm{M}$ nitrogen for higher concentration (+1) and the carbon phosphorus containing compounds were prepared to give $0.04 \mathrm{M}$ phosphorus for the higher level trials (+1). Petroleum oil concentration was kept constant in all trials at the level of $0.5 \%$.

The PB experimental design is based on the first order model [2]:

$$
Y=a_{0}+\sum_{i=1}^{n} a_{i} x_{i}(1)
$$

Where $\mathrm{Y}$ is the response (productivity or specific activity), $a_{0}$ is the model intercept and $a_{\mathrm{i}}$ is the variable estimates. This model describes no interaction among factors and issued to evaluate the important factors that influence petroleum oil bioremediation and fungal growth. Eleven variables were screened in twelve experiments; each variable being either medium constituent or environmental variable. Variables with high confidence levels are considered significant on their effect on petroleum bioremediation.

\section{Screening of significant medium variables by $P B$} design:

The PB design was applied to obtain the estimates of the different culture determinants for petroleum removal by Penicillium chresogenum. A polynomial model for petroleum removal\% was developed by using the estimated coefficients (coded units) and given in Eq. (2).

$$
\begin{gathered}
Y=56.66+0.61 A+3.96 B-9.43 C \\
-1.66 D+25.81 E-5.09 F-6.40 G \\
-3.03 H+3.22 J-2.93 K-2.5 L
\end{gathered}
$$

\section{Results and Discussion}

Twelve experiments were done according to $\mathrm{PB}$ design and the response, petroleum removal was obtained as given in Table 2.The responses were ranging from $4.09 \%$ that was obtained in the combination number 10 to $97.9 \%$ that was obtained in the combination number 9 . Additionally, it can be said that the variability created in the petroleum bioremediation results in the different trials reflects the importance of studying the effect of different variables (either nutritional or environmental) on this microbiological process. Statistical analysis of these data revealed that the value of determination coefficient $\mathrm{R}^{2}$, that measures the goodness of model fitting, is $>0.99$. This indicates that less than $1 \%$ of the total variations is not explained by the model, which ensures the good adjustment of the model (in equation 2) to experimentalize the results.

The factors tested in this design contributed differently on petroleum bioremediation by the Penicillium chresogenum, which means that some of them affected positively and others negatively. Fig. (1) shows that spore suspension, $\left(\mathrm{NH}_{4}\right)_{2} \mathrm{SO}_{4}$, Potassium Carbonate, and Magnesium sulphate promoted petroleum removal by Penicillium chresogenum. While, sodium dihydrogen phosphate, Beef extracts, Temperature, $\mathrm{pH}$, Sodium chloride, $\mathrm{NaCl}$ and $\mathrm{KH}_{2} \mathrm{PO}_{4}$ inhibited the oil bioremediation process. Fig. (2) shows the 
ranking of factor estimates in a Pareto chart. The Pareto chart displays the magnitude of each factor estimate (independent on its contribution, either positive or negative) and is a convenient way to view the results of a PB design (Strobel and Sullivan, 1999). The highest positive significant variable is spore suspension, while $\mathrm{pH}$ is the highest negative significant variable. Shreyasri Dutta and Padma Singh (2014) shows that $\mathrm{Na}_{2} \mathrm{HPO}_{4}$ had a highest contribution where as Peptone and $\mathrm{KH}_{2} \mathrm{PO}_{4}$ had a lowest contribution for the growth of Pseudomonas sp.

\section{Accuracy of the model}

To examine the model validation, a comparison was held between estimated and predicted results as shown in Fig. (3). The linearity of correlation is an evidence of the excellent agreement between experimental and predicted data. The created model (as in equation 2) could be used to predict the response (petroleum removal percentage) when using different culture conditions. It was clear that experimental value were closer to predicted values.

Table (2): PB experimental design for evaluating the effect of different nutritional and environmental categories on oil bioremediation.

\begin{tabular}{|c|c|c|c|c|c|c|c|c|c|c|c|c|}
\hline 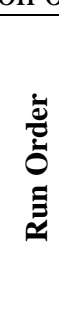 & 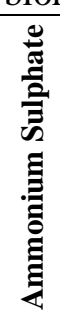 &  &  & 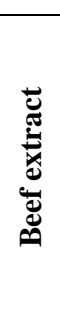 & 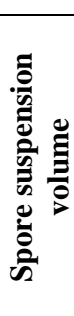 & 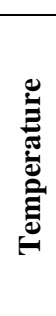 & $\bar{z}$ & 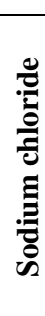 &  & 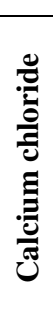 & 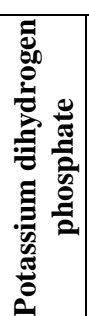 & 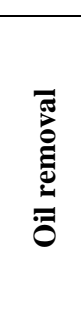 \\
\hline 1 & +1 & +1 & -1 & +1 & +1 & +1 & -1 & -1 & -1 & +1 & -1 & 95.5 \\
\hline 2 & +1 & -1 & +1 & +1 & +1 & -1 & -1 & -1 & +1 & -1 & +1 & 86.19 \\
\hline 3 & -1 & +1 & +1 & +1 & -1 & -1 & -1 & +1 & -1 & +1 & +1 & 22.9 \\
\hline 4 & +1 & +1 & +1 & -1 & -1 & -1 & +1 & -1 & +1 & +1 & -1 & 32.15 \\
\hline 5 & +1 & +1 & -1 & -1 & -1 & +1 & -1 & +1 & +1 & -1 & +1 & 48.43 \\
\hline 6 & +1 & -1 & -1 & -1 & +1 & -1 & +1 & +1 & -1 & +1 & +1 & 77.22 \\
\hline 7 & -1 & -1 & -1 & +1 & -1 & +1 & +1 & -1 & +1 & +1 & +1 & 23.4 \\
\hline 8 & -1 & -1 & +1 & -1 & +1 & +1 & -1 & +1 & +1 & +1 & -1 & 71.2 \\
\hline 9 & -1 & +1 & -1 & +1 & +1 & -1 & +1 & +1 & +1 & -1 & -1 & 97.9 \\
\hline 10 & +1 & -1 & +1 & +1 & -1 & +1 & +1 & +1 & -1 & -1 & -1 & 4.09 \\
\hline 11 & -1 & +1 & +1 & -1 & +1 & +1 & +1 & -1 & -1 & -1 & +1 & 66.8 \\
\hline 12 & -1 & -1 & -1 & -1 & -1 & -1 & -1 & -1 & -1 & -1 & -1 & 54.1 \\
\hline
\end{tabular}

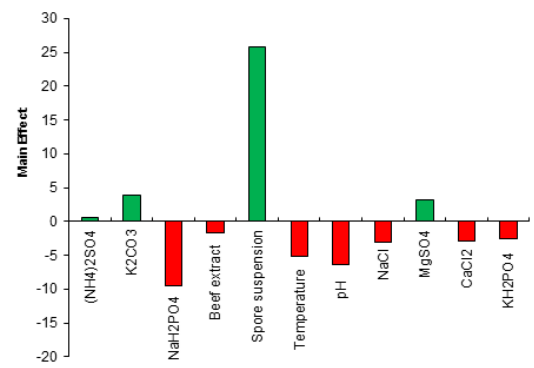

Fig (1): Effects of different culture conditions on petroleum removal $\%$.

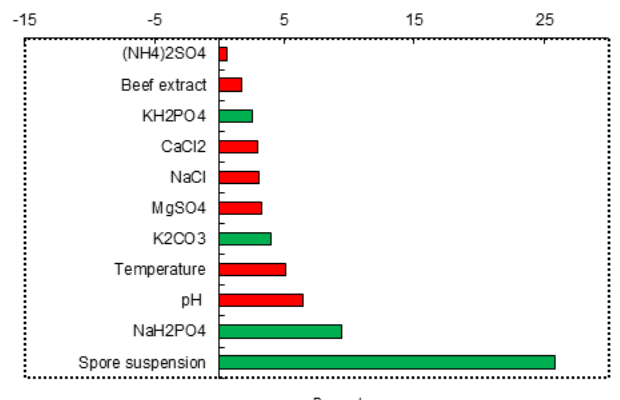

Percent

Fig (2): Pareto plot for PB parameters estimates.

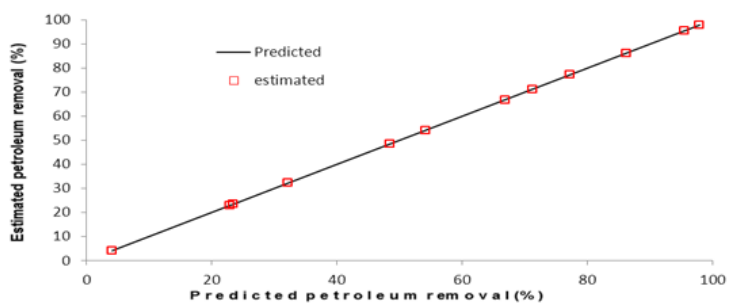

Fig (3): Relation between predicted removal and estimated removal of petroleum.

\section{Conclusion}

Plackett- Burman design is considered a suitable model for choosing the best experiment for hydrocarbon degradation using Pencillium chresogenum. It also evaluates the significance of some variables on the bioprocess, but also in comparing between different categories, in which is difficult to compare between their effects in conventional experiments, and hence maintain a 
comprehensive evaluation of the overall process. It is found that four variables are affected the bioremediation process positively, while others have negative effects on oil bioremediation.

\section{References}

Abdel-Fattah, R., and Hussein, M. (2002): Numerical modeling of petroleum oil bioremediation by a local Penicillium isolate as affected with culture conditions: Application of Plackett-Burman design. Arab J. Biotech.V (5):165-172.

Adam, G., Duncan, H., (2003): The effect of diesel fuel on common vetch (Vicia sativa L.) plants. Environmental Geochemistry and Health 25, 123130.

American Public Health Association (1998): Standard methods for examination of water and wastewater, 20 th edn, Washington D.C., USA.

Ciric, L., Philp, J.C., Whiteley, A.S., (2009): Hydrocarbon utilization within a diesel-degrading bacterial consortium. FEMS Microbiology Letters 303, 116-122.

Heul, (2009): Environmental degradation of petroleum hydrocarbons. $\mathrm{PhD}$, Utrecht University, Netherland, pp., 50.

Krishnan, S., Prapulla, S.G., Rajalakshmi, D., Misra, M.C. and Karanth, N.G. (1998): Screening and selection of media components for lactic acid production using Plackett-Burman design. Bioprocess Eng., 19: 61-65.
Lapinskienè, A., Martinkus, P., Rebždaite, V., (2006): Eco-toxicological studies of diesel and biodiesel fuels in aerated soil. Environmental Pollution 142, 432-437.

Nwachukwu, S.C.U (2000): Enhanced rehabilitation of tropical aquatic environment polluted with crude petroleum using Candida utilis. Journal of Environmental Biology 21(3): 241 - 250.

Plackett, R.L. and Burman, J.P. (1946): The design of optimum multifactorial experiments. Biometrika, 33: 305-325.

Shreyasri Dutta and Padma Singh (2014): The PlackettBurman Model-Optimization of Significant Nutritional Parameters for Petroleum Bioremediation by Pseudomonas sp.V (2), Issue 1, 898-902.

Strobel, R.J. and Sullivan, G.R. (1999): Experimental design for improvement of fermentations. In: Manual of industrial microbiology and biotechnology (Demain, A.L, Davies, J. E., eds.): 80-93. Washington: ASM Press.

Tesar, M., Reichenauer, T.G., Sessitsch, A., (2002): Bacterial rhizosphere populations of black poplar and herbal plants to be used for phytoremediation of diesel fuel. Soil Biology and Biochemistry34, 18831892.

Wang, F.C., Qian, K., Green, L.A., (2005): GCx MS of diesel: a two-dimensional separation approach. Analytical Chemistry 77, 2777-2785.

\section{عنوان البحث: نموذج بلاكت بيرمان لإزالة التلوث البترولي بواسطة عزله فطرة البنسليوم \\ طلعت عبد المنعم حجازي، محموم سالم إبر اهيم، حازم طه عبد الحميد \\ قسم علوم البيئة ، كلية العلوم بدمياط ، جامعة دمياط ، مصر}

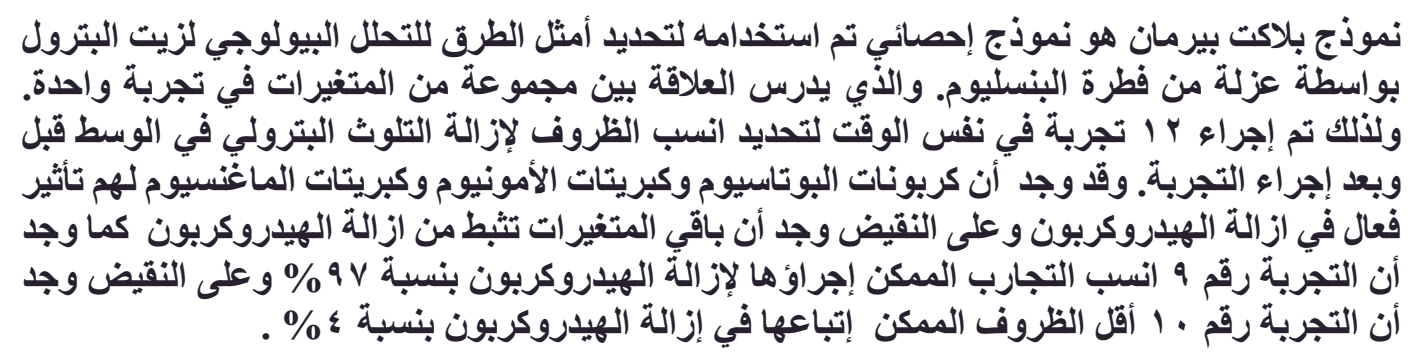

